\title{
Использование ВЭЖХ при определении антоцианов цветков растений семейства Malvaceae
}

\author{
(C) 2020 Дейнека В.И. ${ }^{1}$, Кульченко Я.Ю. ${ }^{1}$, Олейниц Е.Ю. ${ }^{1}$, Дейнека Л.А. ${ }^{1}$, \\ Варушкина С.М. ${ }^{1}$, Чулков А.Н. ${ }^{2}$, Селеменев В.Ф. ${ }^{3}$ \\ ${ }^{1}$ ФГАОУ ВО «Белгородский государственный национальный исследовательский университет», \\ Белгород \\ ${ }^{2}$ ФГБОУ Белгородский филиал «Центр оценки качества зерна и продуктов его переработки», \\ Белгород \\ ${ }^{3}$ ФБОУ ВО «Воронежский государственный университет», Воронеж
}

Поступила в редакцию 11.02.2020 г.

DOI: $10.17308 /$ sorpchrom.2020.20/2769

В работе методом обращенно-фазовой ВЭЖХ был определен набор антоцианов, ответственных за окраску цветков популярного садового растения штокрозы (Altea roseum). 15 антоцианов темноокрашенных цветков представлены 3-глюкозидами, 3-рутинозидами и 3-(6"-малонилглюкозидами) пяти агликонов - трех из дельфинидинового ряда (дельфинидин, петунидин и мальвидин) и двух (цианидин и пеонидин) из цианидинового ряда. Было обнаружено, что цветы накапливают в основном производные дельфинидинового или цианидинового рядов. Количественное соотношение в накоплении различных антоцианов в цветках зависит от сорта штокрозы; установлено, что общее количество антоцианов превышает 1 г на 100 г свежих лепестков для сортов с темной окраской цветков. Зависимость удерживания от структуры веществ исследовали специальными методами относительного анализа удерживания на примере добавления рамнозильной части к 3-глюкозидам и ацилирования малоновой кислотой тех же 3-глюкозидов. Показано, что изменение липофильности (как miLogP), обусловленное усложнением структуры антоцианов, не коррелирует с изменением удерживания растворенного вещества, что, вероятно, связано со специфическим “поплавковым" механизмом удерживания антоцианов. Установлено, что изменение температуры разделения имеет большое значение для контроля селективности разделения антоцианов. И именно изменение температуры от 40 до $27.5^{\circ} \mathrm{C}$ позволило добиться разделения всех 15 антоцианов, в то время как градиентный режим элюирования в этом случае позволяет осуществить разделение менее чем за 20 мин.

Ключевые слова: антоцианы, цветки штокрозы, ВЭЖХ, управление селективностью разделения

\section{Введение}

При хроматографическом способе определения состава сложных смесей единственным измеряемым параметром является время удерживания (кроме высоты и площади пика и некоторых других характеристик, определяемых специальными детекторами). Но время удерживания при заданной скорости подвижной фазы не является надежным параметром при идентификации вещества, поскольку зависит не только от строения вещества, но и от температуры разделения, марки стационарной фазы и геометрических параметров хроматографической колонки, использованной при разделении. Для данной стационарной фазы и при данном составе подвижной фазы и температуре разделения удобной характеристикой, не зависящей от размеров колонки и от скорости подвижной фазы, является фактор удерживания, хотя при вы- 
соком входном сопротивлении потоку возможны заметные отклонения от постоянства [1]. В наиболее часто используемом варианте разделения в обращенно-фазовой ВЭЖХ для выбора условий разделения удобно использовать карту разделения [2], составленную по результатам работы минимум в двух различных составах подвижной фазы. Полученные при этом уравнения относительного удерживания являются уже строгими двухпараметрическими характеристиками хроматографического поведения компонентов смесей антоцианов, и они, по нашему многолетнему опыту, индивидуальны - нам не известны случаи совпадения параметров этих уравнений для двух антоцианов различного строения. Это обеспечивает надежность в идентификации соединений сопоставлением времен удерживания веществ определяемой смеси с удерживанием стандартных смесей.

Стандартные образцы антоцианов не только труднодоступны, но и быстро портятся при хранении. Вероятно, именно поэтому результаты определения антоцианов по двум методам - спектрофотометрическому и хроматографическому, - различаются в несколько раз по данным одной из опубликованных работ [3]. По этой причине нами была начата работа, позволяющая получить легкодоступное растительное сырье для приготовления веществ сравнения при качественном анализе антоцианов. Так, например, плоды черной смородины качественно мало различаются в зависимости от условий выращивания и сорта растения [4]. А их широкая доступность в свежезамороженном виде, простой способ экстракции и очистки позволяют получить набор из четырех часто встречающихся в растительном мире антоцианов.

Многие растения семейства мальвовые (Malvaceae) широко используются в качестве декоративных растений благодаря яркой окраске цветков. При этом окраска цветков штокрозы, Alcea rosea L. от красных до черных определяется биосинтезом в них антоцианов, поэтому цветки некоторых из них можно отнести к нетрадиционным (несъедобным) источникам антоцианов.

В настоящей работе рассмотрена возможность использования в качестве дешевых природных источников суммы антоцианов цветков популярного в садоводстве двухлетнего растения штокрозы. Особый интерес представляли сорта с цветками очень темной окраски (сорта «Шоколад», «Черный вихрь» и др.), что указывало на высокий уровень накопления антоцианов.

\section{Эксперимент}

Разделение осуществляли на оборудовании Agilent 1200 Infinity с диодноматричным и масс-спектрометрическим детекторами. В работе использовали хроматографические колонки: $150 \times 4.6$ мм Symmetry C18 (3.5 мкм) - для серийных исследований и $150 \times 2.1$ мм Kromasil 100-5C18 - при масс-спектрометрическом детектировании. Мертвое время определяли по щавелевой кислоте. Для элюирования использовали элюенты, содержащие 10 об.\% $\mathrm{HCOOH}$ и 6-20 об.\% $\mathrm{CH}_{3} \mathrm{CN}$ в воде. Во всех случаях скорость подачи подвижной фазы была постоянной $-0.8 \mathrm{~cm}^{3} / \mathrm{мин.} \mathrm{Гра-}$ диентный режим, позволяющий разделять все 15 соединений за время менее 19 мин, был построен на элюентах А: 10 об.\% $\mathrm{HCOOH} \mathrm{и} 6$ об. \% $\mathrm{CH}_{3} \mathrm{CN}$ в воде; Б: 10 об.\% $\mathrm{HCOOH} \mathrm{и} 10$ об.\% $\mathrm{CH}_{3} \mathrm{CN}$ в воде; градиентный режим: 0 мин - $0 \%$ Б, 10 мин $-0 \%$ Б, 20 мин $-40 \%$ Б, 30 мин $-100 \%, 31$ мин - 0\% Б, температура $27.5^{\circ} \mathrm{C}$. Хроматограммы регистрировали и обрабатывали программой Agilent ChemStation. Результаты идентификации антоцианов представлены в табл. 1.

Лепестки цветков сушили в лабораторном суховоздушном термостате ТС 1/20 СПУ при $30^{\circ} \mathrm{C}$. Экстракты готовили настаиванием свежих или высушенных лепестков цветков в $0.1 \mathrm{M}$ водном растворе $\mathrm{HCl}$. Перед хроматографированием экстракты, 
отделенные от остатка фильтрованием через бумажный фильтр, очищали методом твердофазной экстракции на концентрирующих патронах Диапак С18 (БиохимМак СТ, Москва) [9].

Таблица 1 Параметры пиков на хроматограммах антоцианов экстракта цветков штокрозы

\begin{tabular}{|c|c|c|c|c|}
\hline №* & Виды антоцианов & $t_{R}$, мин & $\lambda_{\max }, \mathrm{HM}$ & $\mathrm{M} / \mathrm{Z}$ \\
\hline 1 & Дельфинидин-3-глюкозид, Dp3Glu & 2.49 & 525 & $465.2 ; 303,1$ \\
\hline 2 & Дельфинидин-3-рутинозид, Dp3Rut & 2.65 & 526 & $611.2 ; 303,1$ \\
\hline $1 *$ & $\begin{array}{c}\text { Дельфинидин-3-(6"-малонилглюкозид), } \\
\text { Dp3(6"MalGlu) }\end{array}$ & 5.80 & 527 & $551.2 ; 303,1$ \\
\hline 3 & Цианидин-3-глюкозид, Cy3Glu & 3.56 & 518 & $449.1 ; 287.1$ \\
\hline 4 & Цианидин-3-рутинозид, Су3Rut & 3.96 & 520 & $595.2 ; 287.1$ \\
\hline $2 *$ & $\begin{array}{c}\text { Цианидин-3-(6"-малонилглюкозид), } \\
\text { Су3(6"MalGlu) }\end{array}$ & 9.02 & 520 & $535.2 ; 287.1$ \\
\hline 5 & Петунидин-3-глюкозид, Pt3Glu & 4.50 & 526 & $479.2 ; 317,1$ \\
\hline 6 & Петунидин-3-рутинозид, Pt3Rut & 5.05 & 528 & $625.2 ; 317,1$ \\
\hline $3 *$ & $\begin{array}{c}\text { Петунидин-3-(6"-малонилглюкозид), } \\
\text { Pt3(6"MalGlu) }\end{array}$ & 11.31 & 528 & $565.2 ; 317,1$ \\
\hline 7 & Пеонидин-3-глюкозид, Pn3Glu & 6.83 & 522 & $463.2 ; 301,1$ \\
\hline 8 & Пеонидин-3-рутинозид, Pn3Rut & 7.87 & 524 & $609.2 ; 301,1$ \\
\hline $4 *$ & $\begin{array}{c}\text { Пеонидин-3-(6"-малонилглюкозид), } \\
\text { Pn3(6"MalGlu) }\end{array}$ & 15.61 & 525 & $549.2 ; 301,1$ \\
\hline 9 & Мальвидин-3-глюкозид, Mv3Glu & 8.46 & 528 & $493.2 ; 331,1$ \\
\hline 10 & Мальвидин-3-рутинозид, Mv3Rut & 9.58 & 529 & $639.2 ; 331,1$ \\
\hline $5 *$ & $\begin{array}{c}\text { Мальвидин-3-(6"-малонилглюкозид), } \\
\text { Mv3(6"MalGlu) }\end{array}$ & 17.75 & 528 & $579.2 ; 331,1$ \\
\hline
\end{tabular}

* нумерация пиков как на рис.1.

\section{Обсуждение результатов}

На хроматограммах экстрактов цветков штокрозы трех сортов найден богатый спектр антоцианов (до 15 видов), рис. 1, среди которых основными являются 3глюкозиды и 3-рутинозиды пяти обычных антоцианидинов. Найденное число антоцианов заметно больше, чем в известных публикациях [5-7]. Как и в случае антоцианов плодов винограда [8], среди исследованных образцов имеются такие, в которых присутствуют производные в основном как дельфинидинового (т.е. гликозиды дельфинидина, петунидина и мальвидина), так и цианидинового (т.е. производные цианидина и пеонидина) рядов в зависящем от сорта соотношении, табл. 2.

Очевидно также, что хроматограммы, записанные в градиентном режиме, должны быть более удобными при скрининге антоцианов, построенных на сильно различающихся по липофильности основах (антоцианидинах) - от наименее липофильных производных дельфинидина до наиболее липофильных производных мальвидина. Для расчета липофильности антоцианов вследствие наличия заряда во флавилиевой форме из большого числа известных компьютерных программ применима доступная для интерактивного расчета программа Molinspiration (https://www.molinspiration.com/), позволяющая рассчитывать параметр липофиотности miLogP (приведен в скобках для ряда 3-глюкозидов):

Dp3Glu(-3.08) < Cy3Glu(-2.79) < Pt3Glu(-2.78) < Pn3Glu(-2.49) < Mv3Glu(-2.47). 


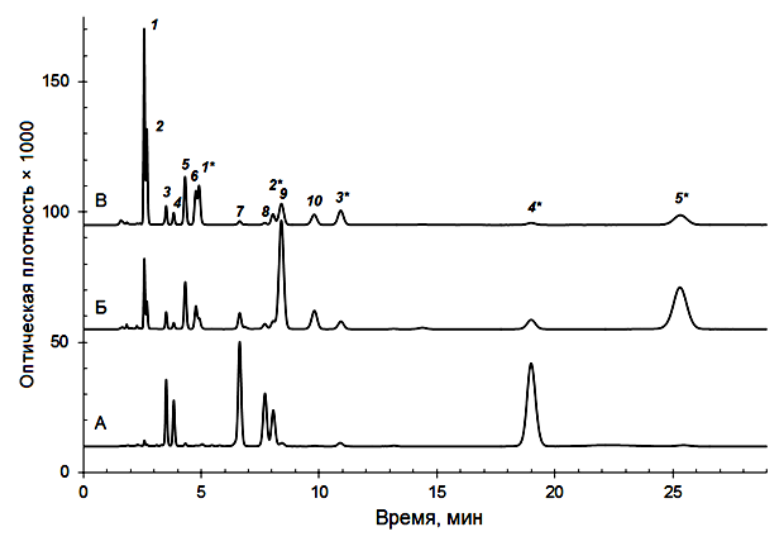

Рис. 1. Разделение антоцианов экстракта цветков трех неизвестных сортов штокрозы.

Разделение в элюенте 10 об. \% $\mathrm{CH}_{3} \mathrm{CN}$ и 10 об. \% HCOOH в воде. Антоцианы: 1 - Dp3Glu, 2 - Dp3Rut, 3 - Cy3Glu, 4 - Cy3Rut, 5 - Pt3Glu, 6 - Pt3Rut, 7 - Pn3Glu, 8 - Pn3Rut, 9 - Mv3Glu, 10 - Mv3Rut, звездочкой отмечены 3-глюкозиды соответствующих агликонов, ацилированные малоновой кислотой.

Таблица 2. Видовой состав антоцианов в цветках некоторых сортов штокрозы.

\begin{tabular}{|c|c|c|c|c|c|}
\hline \multirow{2}{*}{ Виды антоцианов } & \multicolumn{5}{|c|}{ Сорта штокрозы } \\
\cline { 2 - 6 } & $\begin{array}{c}\text { «Красная } \\
\text { Дама» }\end{array}$ & $\begin{array}{c}\text { «Черная } \\
\text { Дама» }\end{array}$ & $\begin{array}{c}\text { «Алая да- } \\
\text { ма» }\end{array}$ & $\begin{array}{c}\text { красная } \\
\text { окраска* }\end{array}$ & $\begin{array}{c}\text { розовая } \\
\text { окраска* }\end{array}$ \\
\hline $\begin{array}{c}\text { Дельфинидин-3- } \\
\text { глюкозид }\end{array}$ & 4.7 & 15.3 & 0.0 & 0.0 & 0.0 \\
\hline $\begin{array}{c}\text { Дельфинидин-3- } \\
\text { рутинозид }\end{array}$ & 1.1 & 14.4 & 0.0 & 0.0 & 0.0 \\
\hline Цианидин-3-глюкозид & 0.47 & 5.4 & 10.9 & 14.8 & 19.5 \\
\hline Цианидин-3-рутинозид & 0.32 & 6.2 & 10.7 & 7.3 & 4.5 \\
\hline Петунидин-3-глюкозид & 7.1 & 6.7 & 0.0 & 0.0 & 0.0 \\
\hline Петунидин-3-рутинозид & 4.1 & 12.2 & 0.0 & 0.0 & 0.0 \\
\hline Пеонидин-3-глюкозид & 1.3 & 1.9 & 42.2 & 46.9 & 59.8 \\
\hline Пеонидин-3-рутинозид & 0.95 & 12.3 & 29.1 & 29.7 & 12.2 \\
\hline Мальвидин-3-глюкозид & 50.8 & 8.8 & 0.0 & 0.0 & 0.0 \\
\hline Мальвидин-3-рутинозид & 27.1 & 13.8 & 0.0 & 0.0 & 0.0 \\
\hline Остальные & 2.1 & 2.98 & 6.9 & 1.2 & 3.9 \\
\hline $\begin{array}{c}\text { Содержание мг на 100 } \\
\text { грамм лепестков }\end{array}$ & 950 & 1750 & 750 & 550 & 230 \\
\hline
\end{tabular}

* сорт неизвестен

Отметим, что кроме 3-цианидинов и 3-рутинозидов в экстракте могут обнаруживаться и производные другого типа. Их отнесение к одному и тому же типу подтверждается в диаграммах, подобных диаграммам соединений сходственных типов, предложенных М.X Карапетьянцем [9], рис. 2. Так, например, удерживание всех 3-рутинозидов (X3Rut) относительно 6-глюкозидов (X3Glu) соответствующих антоцианидинов при записи хроматограммы в некоторых условиях описывается зависимостью:

$$
\lg \boldsymbol{k}(\mathrm{X} 3 \mathrm{Rut})=1.028 \cdot \lg \boldsymbol{k}(\mathrm{X} 3 \mathrm{Glu})+0.076 \text {. }
$$

Это уравнение показывает, что введение рамнозильного радикала в положение 6'-глюкозидного заместителя приводит к росту удерживания, близкому для всех агликонов (с небольшим увеличением с ростом липофильности основы), причем рост времен удерживания составляет немногим меньше 20\%, табл. 3. Это важно, например, при идентификации антоцианов по данным масс-спектров. Если за основу 
при предсказании удерживания антоцианов брать изменение miLogP при введении рамнозильного радикала в глюкозидный, то следовало бы вообще ожидать существенное падение удерживания: miLogP уменьшается, например, для цианидин-3глюкозида при такой замене от -2.79 до -3.49.

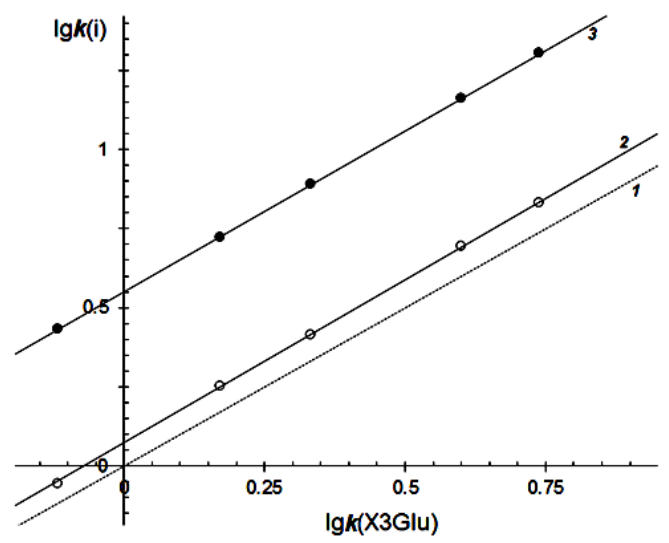

Рис. 2. Сравнительная диаграмма удерживания однотипных гликозидов пяти антоцианидинов в элюенте 9 об.\% $\mathrm{CH}_{3} \mathrm{CN}$ и 10 об. \% НСООН в воде.

1 - 3-глюкозиды, 2 - 3-рутинозиды, 3 - 3-глюкозды, ацилированные малоновой кислотой в положение 6".

Найденное несоответствие не удивительно, поскольку для антоцианов справедлив «поплавочный» механизм удерживания [10]. При таком механизме удерживания антоцианидиновая часть молекулы (точнее, молекулярного иона) проникает внутрь привитой фазы, а углеводная часть остается на поверхности этой фазы и рост удерживания при указанной замене связан с наличием липофильной метильной группы в рамнозильном радикале, также способной проникать в привитую фазу.

Таблица 3. Параметры удерживания, $\lg \boldsymbol{k}(\mathrm{i})$, антоцианов штокрозы в элюенте 9 об.\% $\mathrm{CH}_{3} \mathrm{COOH}, 10$ об.\% НСООН в воде

\begin{tabular}{|c|c|c|c|c|c|c|}
\hline \multirow[b]{2}{*}{ № } & \multirow[b]{2}{*}{ Антоцианидины } & \multicolumn{3}{|c|}{$\lg \boldsymbol{k}(\mathrm{i})$ гликозидов $( \pm 0.001)$ : } & \multicolumn{2}{|c|}{ Рост удерживания } \\
\hline & & $3 \mathrm{Glu}$ & 3Rut & 3(6”MalGlu) & $\Delta(\mathrm{Glu} \rightarrow \mathrm{Rut})$ & $\underset{\text { 6"MalGlu })}{\Delta(\mathrm{Glu} \rightarrow}$ \\
\hline 1 & Дельфинидин, Dp & -0.120 & -0.060 & 0.434 & 0.062 & 0.551 \\
\hline 2 & Цианидин, Су & 0.170 & 0.253 & 0.723 & 0.083 & 0.553 \\
\hline 3 & Петунидин, $\mathrm{Pt}$ & 0.333 & 0.414 & 0.892 & 0.081 & 0.559 \\
\hline 4 & Пеонидин, Pn & 0.599 & 0.696 & 1.161 & 0.097 & 0.562 \\
\hline 5 & Мальвидин, Mv & 0.738 & 0.833 & 1.304 & 0.095 & 0.566 \\
\hline \multicolumn{5}{|c|}{ Стандартное отклонение. $\mathrm{s}$} & 0.014 & 0.006 \\
\hline \multicolumn{5}{|c|}{ Среднее значение, $\bar{\Delta}$} & 0.072 & 0.466 \\
\hline \multicolumn{5}{|c|}{ Кратность роста удерживания, раз } & 1.18 & 2.924 \\
\hline
\end{tabular}

Учтем, что рост массы антоциана одинаков как при добавлении рамнозильного радикала, так и при ацилировании глюкозидного радикала парa-кумаровой кисло-

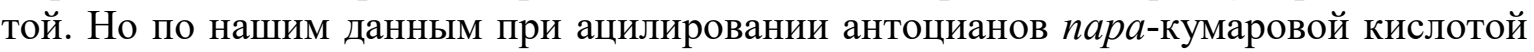
время удерживания возрастает примерно в 20 раз. Не учёт этого фактора привел к ошибочной идентификации антоцианов цветков катарантуса [11].

Для ацилированных малоновой кислотой в положение 6 глюкозидного радикала антоцианов получена также линейная зависимость:

$$
\lg \boldsymbol{k}[\mathrm{X} 3(6 ” \mathrm{MalGlu})]=1.018 \cdot \lg \boldsymbol{k}(\mathrm{X} 3 \mathrm{Glu})+0.552 \text {. }
$$


Положение ацилирования глюкозидного заместителя малоновой кислотой было определено сопоставлением удерживания антоцианов штокрозы с антоцианами пурпурной кукурузы [12]. Рост удерживания при таком ацилировании оказывается существенно более высоким, чем при добавлении рамнозильного радикала, что противоречит уменьшению параметра липофильности при ацилировании малоновой кислотой: miLogP уменьшается от -2.79 до -3.09. Тем не менее, для всех антоцианидинов рост удерживания оказался немногим менее 3-х кратного. При этом важность влияния ориентации малонильного радикала в глюкозидном заместителе на удерживание антоциана отмечалась в работе [12].

Анализ экстрактов многих сортов штокрозы (часто неизвестного сорта) показал, что не только соотношение между производными различных антоцианидинов, но и степень ацилирования могут существенно различаться, рис. 1, но при длительном выдерживании экстрактов в холодильнике малоновая кислота постепенно удаляется [13], оставляя в растворе только смесь 3-глюкозидов и 3-рутинозидов. При этом основная хроматографическая проблема в данном случае - трудность в разделении соединений: пары Pt3Rut и Dp3(6"MalGlu) с одной стороны и трех веществ Pn3Rut, Cy3(6"MalGlu) и Mv3Glu - с другой. Эта проблема легко решается изменением температуры разделения, рис. 3.

Очевидно, что удерживание малонированных производных существенно сильнее зависит от температуры, что соответствует большей по абсолютной величине энтальпии экзотермического процесса переноса веществ из подвижной фазы на стационарную.

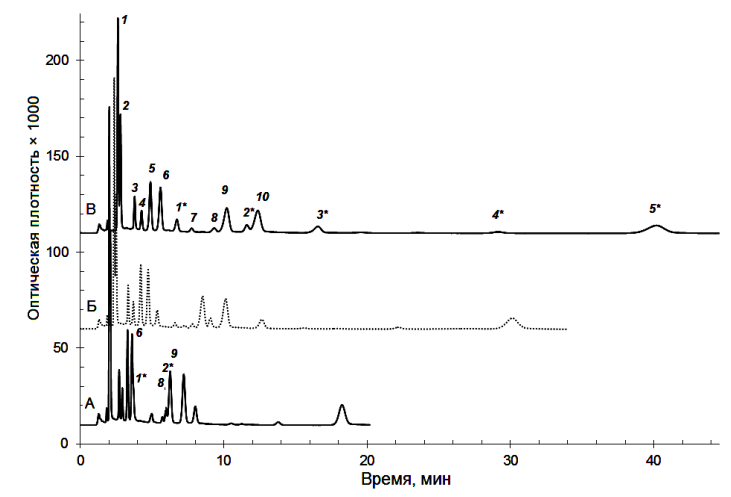

Рис. 3. Разделение антоцианов экстракта цветков штокрозы при трех различных температурах. Температура $\mathrm{A}-40^{\circ} \mathrm{C}$; Б $-30^{\circ} \mathrm{C}$; $\mathrm{B}-25^{\circ} \mathrm{C}$. Разделение в элюенте 10 об. \% $\mathrm{CH}_{3} \mathrm{CN}$ и 10 об. \%

$\mathrm{HCOOH} \mathrm{в} \mathrm{воде.} \mathrm{Температура:} \mathrm{A}-40^{\circ} \mathrm{C} ; \mathrm{A}-$ $30^{\circ} \mathrm{C} ; \mathrm{A}-25^{\circ} \mathrm{C}$. Нумерация антоцианов см. рис. 1 .

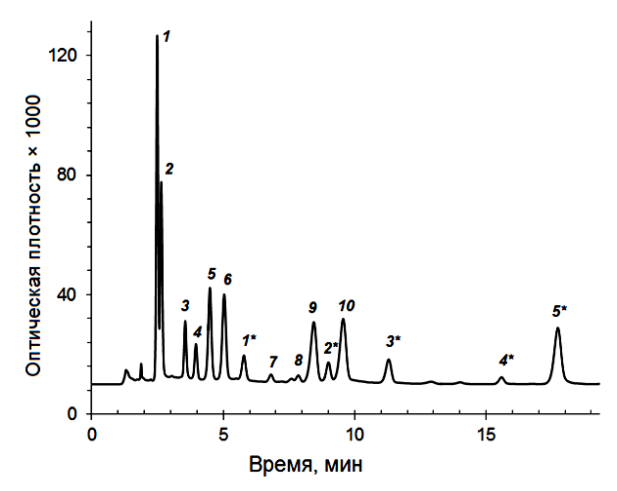

Рис. 4. Разделение антоцианов экстракта цветков штокрозы в градиентном режиме. Температура: $27.5^{\circ} \mathrm{C}$.

Нумерация антоцианов см. рис.1.

При этом, сопоставляя разделение всех компонентов при исследованных температурах можно сделать вывод о том, что оптимальной будет температура $27.5^{\circ} \mathrm{C} \mathrm{c}$ изменением изократического режима на градиентный (для сокращения времени полного разделения до 19 мин), рис. 4.

\section{Заключение}

Таким образом, цветки популярного у садоводов-любителей растения штокроза темной (почти черной) окраски являются уникальными источниками комплекта 15 антоцианов - 3-глюкозидов, 3-рутинозидов и 3-(6"-малонилглюкозидов). И если набор 3-глюкозидов и 3-рутинозидов по нашим данными синтезируется в плодах 
магонии падуболистной [14], то другой источник пяти малонированных 3глюкозидов нами не был нами пока обнаружен.

\title{
Список литературы
}

1. Martina M., Guiochon G. // J. Chromatogr. A. 2005. Vol. 1090. pp. 16-38.

2. Дейнека В.И. // Журн. физ. химии. 2006. T. 80. № 3. C. 511-516.

3. Lee J., Rennaker C., Wrolstad R.E. // Food Chem. 2008. Vol. 110. pp. 782-786.

4. Дейнека Л.А., Шапошник Е.И., Гостищев Д.А. и др. // Сорбиионные и хроматографические проиессы. 2009. Т. 9. № 4. С. 529-536.

5. Hosaka H., Mizuno T., Iwashina T. // Bull. Natl. Mus. Nat. Sci. Ser. B. 2012. Vol. 38. pp. 69-75.

6. Fahamiya N., Shiffa M., Aslam M. // Indo Amer. J. Pharm. Res. 2016. Vol. 6. pp 68886894.

7. Takeda K., Enoki S., Harborne J.B. et al. // Phytochem. 1989. Vol. 28. pp. 499-500.

8. Дейнека Л.А., Литвин Ю.Ю., Дейнека В.И. // Научные ведомости БелГУ. Серия: Естественные науки. 2008. №7(47). Вып.7.

9. Дейнека В.И., Кульченко Я.Ю., Чулков А.Н. и др. // Журн. физ. химии. 2019. Т. 93. С. 790-792.

10 Дейнека В. И., Дейнека Л.А., Саенко И.И. и др. // Журн. физ. химии. 2015, Т. 89. С. 1172-1177.

11. Piovan A., Filippini R., Favretto D. // Rapid Commun. Mass Spectrom. 1998. Vol. 12. pp. 361-367.

12. Дейнека В.И., Сидоров А.Н., Дейнека Л.А. // Журн. аналит. химии. 2016. Т. 71. С. 1203-1208.

13. Дейнека В.И., Сидоров А.Н., До Ван Куи и др. // Сорбиионные и хроматографические проиессы. 2017. Т. 17. № 4. С. 542547.

14. Сорокопудов В.Н., Хлебников В.А., Дейнека В.И. // Химия растительного сырья. 2005. № 4. С. 57-60.

C. 71-78.

\section{Utilization of HPLC in the search for non-traditional sources of anthocyanins. Anthocyanins of flowers of plants of the Malvaceae family}

\author{
(C) 2020 Deineka V.I. ${ }^{1}$, Kulchenko Ya.Yu. ${ }^{1}$, Olenits E.Yu. ${ }^{1}$, Deineka L.A. ${ }^{1}$, \\ Varushkina S.M. ${ }^{1}$, Chulkov A.N. ${ }^{2}$, Selemenev V.F. ${ }^{3}$ \\ ${ }^{1}$ Belgorod National Research University, Belgorod \\ ${ }^{2}$ Belgorod branch of "Centre of evaluation of quality of grain and products of its processing», Belgorod \\ ${ }^{3}$ Voronezh State University, Voronezh
}

In the study, reversed-phase HPLC was used to determine a set of anthocyanins responsible for the colouring of the flowers of a popular garden plant, hollyhock (Altea roseum). 15 anthocyanins in darkcoloured flowers are represented by 3-glucosides, 3-rutinosides, and 3-(6"-malonylglucosides) of five aglicons: three of the delphinidin series (delpninidin, petunidin, and malvidin) and two (cyanidin and peonidin) of the cyanidin series. It was revealed that the flowers mainly accumulate derivatives of the delphinidine or cyanidine series. The quantitative ratio of various anthocyanins in flowers depends on the variety of hollyhock cultivar; the overall accumulation of anthocyanins was found to exceed $1 \mathrm{~g}$ per $100 \mathrm{~g}$ of fresh petals for cultivars with dark-coloured flowers. The dependence of retention on the substance structure was investigated by special methods of relative retention analysis based on the example of rhamnosyl moiety added to 3glucosides and malonic acid acylation of the same 3-glucosides. It was shown that the change in lipophilicity (as miLogP), due to the complexity of the anthocyanin structure, does not correlate with the change in the retention of the solute, which is probably due to a specific "float" mechanism of anthocyanin retention. It was also established that the variation of the separation temperature might be of great importance in controlling the selectivity of anthocyanin separation. Namely, a temperature alteration from $40^{\circ} \mathrm{C}$ to $27.5^{\circ} \mathrm{C}$ made it possible to achieve separation of all 15 anthocyanins, while a gradient elution mode in this case permits to perform the separation within less than 20 minutes.

Keywords: anthocyanin, flowers, hollyhock, Altea roseum, RP HPLC, control of separation selectivity 


\section{References}

1. Martina M., Guiochon G., J. Chromatogr. A, 2005, Vol. 1090, pp. 16-38. https://doi.org/10.1016/j.chroma.2005.06.005

2. Deineka V.I., Russ. J. Phys. Chem., 2006, Vol. 80, pp. 429-434. https://doi.org/10.1134/S0036024406030204

3. Lee J., Rennaker C., Wrolstad R.E., Food Chem., 2008, Vol. 110, pp. 782-786. DOI: 10.1016/i.foodchem.2008.03.010

4. Dejneka L.A., Shaposhnik E.I., Gostishchev D.A. et al., Sorbtsionnye i khromatograficheskie protsessy, 2009, Vol. 9, No 4, pp. 529-536. [in Russian].

5. Hosaka H., Mizuno T., Iwashina T., Bull. Natl. Mus. Nat. Sci. Ser. B, 2012, Vol. 38, pp. 69-75.

6. Fahamiya N., Shiffa M., Aslam M., Indo Amer. J. Pharm. Res., 2016, Vol. 6(11), pp. 6888-6894.

7. Takeda K., Enoki S., Harborne J.B. et al., Phytochem., 1989, Vol. 28, pp. 499-500. https://doi.org/10.1016/0031-9422(89)80040-8

8. Deineka L.A., Litvin Yu.Yu., Deineka V.I., Nauchnye vedomosti BelGU. Seriya: Estestvennye nauki, 2008, No 7(47), Vyp.7, pp. 71-78. [In Russian].

Дейнека Виктор Иванович - профессор кафедры общей химии, д.х.н., Белгородский государственный национальный исследовательский университет, Белгород

Кульченко Ярослава Юрьевна - аспирант кафедры общей химии Белгородский государственный национальный исследовательский университет, Белгород

Олейниц Елена Юрьевна - аспирант кафедры общей химии Белгородский государственный национальный исследовательский университет, Белгород

Дейнека Людмила Александровна - доцент кафедры общей химии, к.х.н., Белгородский государственный национальный исследовательский университет, Белгород

Варушкина Светлана Михайловна - старший преподаватель кафедры общей химии, к.б.н., Белгородский государственный национальный исследовательский университет, Белгород

Чулков Андрей Николаевич - старший специалист, Белгородский филиал «Центр оценки качества зерна и продуктов его переработки», Белгород

Селеменев Владимир Федорович - д.х.н., проф., зав. каф. аналитической химии химического факультета Воронежского государственного университета, Воронеж
9. Deineka V.I., Kul'chenko Ya.Yu., Chulkov A.N. et al., Russ. J. Phys. Chem. A, 2019, Vol. 93, No 5, pp. 997-999 DOI: $10.1134 / \mathrm{S} 003602441905008 \mathrm{X}$.

10. Deineka V.I., Deineka L.A., Saenko I.I., et al., Russ. J. Phys. Chem. A, 2015, Vol. 89, No 7 , pp. $1300-1304$. DOI: 10.1134/S0036024415070079.

11. Piovan A., Filippini R., Favretto D., Rapid Commun. Mass Spectrom., 1998, Vol. 12, pp. 361-367. https://doi.org/10.1002/(SICI)10970231(19980415)12:7<361::AID-

RCM162>3.0.CO;2-U

12. Deineka V.I., Sidorov A.N., Deineka L.A., J. Anal. Chem., 2016, Vol. 71, No 11, pp. 1145-1150.

https://doi.org/10.1134/S1061934816110034.

13. Deineka V.I., Sidorov A.N., Do Van Kui et al., Sorbtsionnye $i$ khromatograficheskie protsessy, 2017, Vol. 17, No 4, pp. 542-547. [in Russian].

14. Sorokopudov V.N., Hlebnikov V.A., Dejneka V.I., Khimiya rastitel'nogo syr'ya, 2005, No 4, pp. 57-60.

Deineka Viktor I. - Professor of the Department of General Chemistry Belgorod state national research University, Belgorod, e-mail deineka@bsu.edu.ru

Kulchenko Yaroslava Yu. - post-graduate of the Department of General Chemistry Belgorod state national research University, Belgorod, e-mail kulchenko.1992@mail.ru

Oleinits Elena Yu. - post-graduate of the Department of General Chemistry Belgorod state national research University, Belgorod, e-mail 812887@bsu.edu.ru

Deineka Lyudmila A. - Associate Professor of the Department of General Chemistry Belgorod state national research University, Belgorod, e-mail deyneka@bsu.edu.ru

Varushkina Svetlana M. - senior lecturer of the Department of General Chemistry Belgorod state national research University, Belgorod, e-mail varushkina@bsu.edu.ru

Chulkov Andrey N. - senior specialist, Belgorod branch "center for quality assessment of grain and products of its processing", Belgorod, e-mail afh87@mail.ru

Selemenev Vladimir F. - the professor, head of the department of Analitical chemistry, Voronezh State University, Voronezh 